\title{
ALGUNS ASPECTOS DE IMUNOENSAIOS APLICADOS À QUÍMICA ANALÍTICA
}

Eric de Souza Gil e Lauro Tatsuo Kubota

Departamento de Química Analítica - IQ - Unicamp - CP 6154 - 13083-970 - Campinas - SP

Yoshimi Imoto Yamamoto

Departamento de Análises Clínicas - FCF - USP - São Paulo - SP

Recebido em 14/8/98; aceito em 29/1/99

\begin{abstract}
SOME ASPECTS OF IMMUNOASSAYS APPLIED TO ANALYTICAL CHEMISTRY. In the last years, the use of antibody-antigen interactions, has earned attention not only for clinical analysis, but also for food industry and environmental control. Since the scope and diversity of immunoassay technology have shown a wide development. Continuous advances in order to analyse complex matrices, to improve reliability, simplicity (nonseparation) and to get multiple simultaneous assays, and extreme sensitivity (lower than zeptomole detection limits) are increasing. Many strategies have been investigated including chemiluminescent enzyme immunoassays, DNA as label and development of flow injection and immunosensors techniques. This subject became very usefull and important in nowadays that are taught in the undergraduate courses of chemistry in the european universities. However in our country are still ignored in the chemistry course.
\end{abstract}

Keywords: imunoassays; imunosensors; clinical analysis.

\section{INTRODUÇÃO}

Nos últimos anos, a combinação da Imunologia à Química Analítica bastante explorada em análises clínicas ${ }^{1-4}$, tem despertado o interesse de outras áreas, entre estas, a ambiental ${ }^{5-11}$, ocupacional $^{12}$ e de alimentos ${ }^{6,10,12-16}$. Uma das razões que tem influenciado este fato é o crescente rigor nas fiscalizações do meio ambiente e de alimentos, por parte de entidades nacionais e internacionais, tornando-se urgente a necessidade de desenvolver técnicas rápidas e seletivas para uma grande variedade de analitos.

Uma das primeiras técnicas imunoanalíticas relatadas foi a imunopreciptação. Trata-se de técnica semiquantitativa, que vem sendo usada até hoje em testes negativo/positivo ${ }^{17}$. O radioimunoensaio constituiu-se num grande avanço no campo de imunoensaios (IAs) quantitativos ${ }^{18}$, seguido pelo surgimento de enzima-imunoensaios (EIAs) como ELISA (Enzyme Linked Immunosorbent Assays) e EMIT (Enzyme Multiplied Immuno Technique), tendo enzimas como meio alternativo de detecção ${ }^{7,13}$. Outros avanços como o desenvolvimento de sistemas de injeção em fluxo acoplados a imunoensaios (FI-IAs) ${ }^{7,19}$, imunossensores $^{20-23}$ e cromatografia por imunoafinidade ${ }^{4,24}$ complementam os esforços empregados até aqui, no aperfeiçoamento e utilização de imunoensaios aplicados à Química Analítica.

O fator mais marcante em imunoanálises é o ganho em seletividade, dada a grande especificidade de anticorpos (Ac) por seus antígenos $(\mathrm{Ag})^{25}$. De maneira geral, além da seletividade, os IAs apresentam, também dependendo do marcador e ou sistema de detecção empregado ${ }^{7,26-28}$, boa sensibilidade ${ }^{28,29}$.

Entre as principais desvantagens encontradas nos métodos convencionais de imunoanálises estão a significativa complexidade associada a sua automação e longo tempo de análise ${ }^{12,26}$. Neste sentido, a fusão de imunoensaios clássicos com outras metodologias analíticas ${ }^{7}$ constitui-se numa saída para superar estas desvantagens e expressa-se no desenvolvimento e aperfeiçoamento de imunossensores ${ }^{30-34}$, FI-IAs ${ }^{2,7,19}$ e cromatografia por bioafinidade $4,24,35$.

Pretende-se relatar alguns avanços recentes relacionados a imunoensaios aplicados a diversas áreas da Química Analítica, bem como expor brevemente alguns conceitos e princípios básicos relacionados à imunologia e aos imunoensaios. Convém ainda lembrar que, apesar da importância do tema o mesmo vem sendo pouco estudado nos cursos de graduação e pós graduação em Química.

\section{ASPECTOS BÁSICOS DE IMUNOLOGIA}

Imunologia é a ciência que estuda os mecanismos de defesa dos organismos vivos, em particular de humanos ou outros mamíferos. De uma maneira bem simples, a resposta imunológica de organismos vivos (exceto plantas) se dá pelo contato com antígenos, com produção de anticorpos. Os antígenos (substâncias imunogênicas) são capazes de desencadear reação em cadeia (Fig. 1), ativando linfócitos (glóbulos brancos) e síntese de anticorpos específicos (sistema imune humoral) ${ }^{36}$.

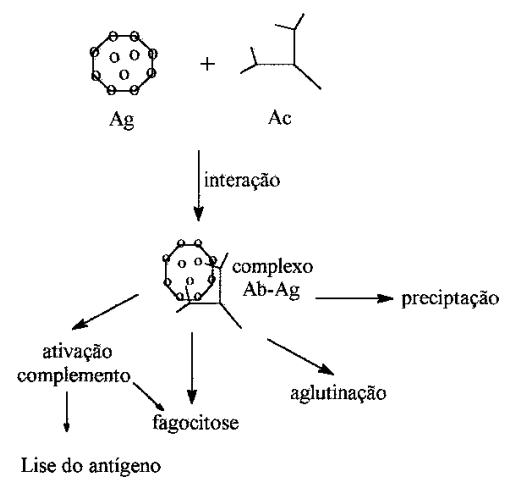

Figura 1. Esquema simplificado de uma resposta imunológica.

Os anticorpos são proteínas de alto peso molecular PM ( $150 \mathrm{kD})$, já os antígenos devem possuir, além de certa complexidade química que os diferencie das substâncias reconhecidas pelo organismo, pelo menos $1 \mathrm{kD}$. Para ilustrar, citam-se como exemplo o polietileno-glicol que possui PM maior que 1 $\mathrm{kD}$, mas não apresenta complexidade química necessária, em contrapartida muitos agrotóxicos e fármacos apresentam complexidade química, mas PM muito menor que $1 \mathrm{kD}^{36}$. 
Os anticorpos também são chamados de imunoglobulinas (Ig) (Fig. 2) que possuem duas cadeias "leves" (25 kD) e duas cadeias pesadas $(50 \mathrm{kD})$, as quais são ligadas entre si por pontes de dissulfeto, formando estrutura simétrica em Y. As cadeias têm sua porção amino terminal próxima ao topo da estrutura em Y, onde se encontra o sítio determinante do anticorpo, denominado fragmento $\mathrm{F}_{\mathrm{ab}}{ }^{37}$. As seqüências dos aminoácidos neste fragmento determinam a especificidade do anticorpo e o tipo de imunoglobulina, as quais são agrupadas em 5 classes principais (Tabela 1)

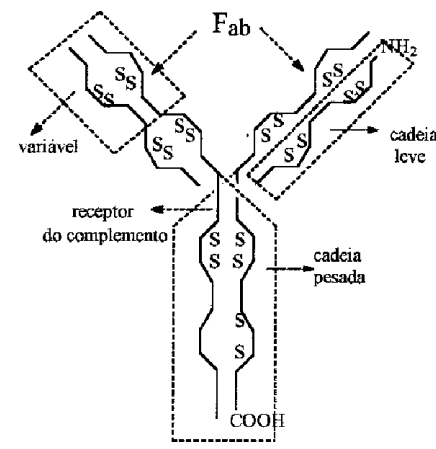

Figura 2. Estrutura genérica de imunoglobulinas (anticorpo).

Tabela 1. Propriedades e abundância de imunoglobulinas ${ }^{38}$.

\begin{tabular}{|c|c|c|}
\hline Classe & $\begin{array}{l}\text { Concentração } \\
\text { em soro de adulto }\end{array}$ & Propriedades características \\
\hline $\operatorname{IgG}$ & $12 \mathrm{mg} / \mathrm{mL}$ & único que atravessa placenta \\
\hline $\mathrm{IgE}$ & $0,3 \mathrm{mg} / \mathrm{mL}$ & predominante na resposta alérgica \\
\hline $\operatorname{IgM}$ & $1,0 \mathrm{mg} / \mathrm{mL}$ & $\begin{array}{l}\text { lisa bactéria por ativação de outros } \\
\text { componentes do soro }\end{array}$ \\
\hline $\operatorname{Ig} \mathrm{A}$ & $1,8 \mathrm{mg} / \mathrm{mL}$ & $\begin{array}{l}\text { encontrado em secreções } \\
\text { (saliva e lágrima) }\end{array}$ \\
\hline $\operatorname{IgD}$ & $30 \mathrm{mg} / \mathrm{mL}$ & encontrado em linfócitos \\
\hline
\end{tabular}

Já os antígenos podem ser classificados em uni ou multideterminados e uni ou multivalentes ${ }^{39}$. Os primeiros relacionam-se à possibilidade de se ter um ou mais tipos de epitopos (grupos funcionais determinantes na interação AgAc), os segundos se relacionam à repetição de cada tipo de epitopo (Fig. 3).
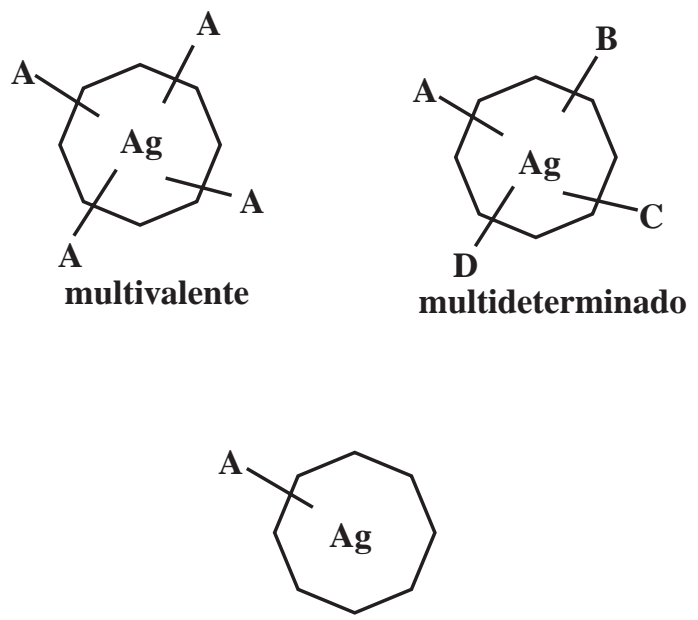

\section{univalente e unideterminado}

Figura 3. Classificação de antígenos quanto ao número de epitopos $(A, B, C, D)$.
A interação Ag-Ac é relativamente fraca, envolvendo ligações não covalentes como Wan der Waals, eletrostática, ligação de hidrogênio e ligações hidrofóbicas ${ }^{40}$. Estas interações ocorrem a curta distância, de modo que, só moléculas contendo determinante antigênico ou muito similares (reatividade cruzada) ligam ao sítio antígeno ligante do respectivo anticorpo ${ }^{41}$.

\section{PRINCÍPIOS BÁSICOS EM IMUNOENSAIOS}

Considerando que, aproximadamente 500.000 produtos químicos estão em uso no mundo atual, e centenas de novos produtos são lançados no mercado anualmente ${ }^{29}$, a necessidade de se desenvolver técnicas analíticas de alta seletividade, faz-se inevitável. Entretanto a viabilidade do método muitas vezes pode não se fazer justificável. Antes de se iniciar o planejamento de metodologia imunoanalítica, deve-se ter em mente alguns princípios básicos. Uma limitação óbvia em imunoensaios seria em relação ao PM, uma vez que muitos analitos de interesse em Química Ambiental, de indústrias de alimentos bem como em análises clínicas constituem-se em moléculas de PM menor que $1 \mathrm{kD}$. Este fato impossibilitaria a resposta imunológica com produção de anticorpos seletivos para estes analitos. Entretanto, pode-se solucionar este problema conjugando estas espécies a macromoléculas (proteínas transportadoras como albumina). As moléculas dos analitos pequenas com potencial imunogênico são denominadas haptenos ${ }^{42}$. Grupos $\mathrm{NH}_{2}, \mathrm{COOH}, \mathrm{SH}, \mathrm{OH}, \mathrm{CO}$ e HCO normalmente, são os principais pontos de conjugação envolvidos neste evento. Outra dificuldade a ser vencida é a lentidão das reações imunológicas ${ }^{17,28}$. O acoplamento a FIA foi recentemente revisado ${ }^{19}$ e constitui-se na melhor solução para diminuir o tempo de IAs.

Outro ponto importante, que deve ser bem pré-estabelecido no planejamento de imunoensaios diz respeito aos sistemas de detecção. Estes definirão a escolha de marcadores adequados, os quais devem apresentar boa estabilidade e sensibilidade, baixo custo, fácil conjugação e detecção ${ }^{28}$.

A Tabela 2 mostra alguns dos principais sistemas de detecção e respectivos marcadores utilizados em IAs ${ }^{21,34,43,44}$.

Tabela 2. Sistema de detecção e exemplos de marcadores.

\begin{tabular}{cc}
\hline Sistema de Detecção & Exemplos de marcadores \\
\hline Eletroquímicos & enzimas: peroxidases, oxidases ... \\
Radioativos & isótopos: ${ }^{125} \mathrm{I},{ }^{14} \mathrm{C},{ }^{3} \mathrm{H}$ \\
Piezoelétricos* & macromoléculas (Anticorpos) \\
Fluorimétricos & fluoresceína, quelatos de lantanídeos \\
Luminométricos & luminol, isoluminol, lucigenina, acridina \\
\hline
\end{tabular}

* sistema de detecção direta, os demais são, na maioria, indiretos.

Por fim, dependendo do sistema de detecção empregado, pode-se definir o formato do imunoensaio, o qual basicamente, se divide em homogêneos e heterogêneos. Sendo que no primeiro caso, para detecção não se faz necessária a separação, entre espécies marcadas e livres. O fluxograma da Figura 4 ilustra todas etapas envolvidas no planejamento de um imunoensaio.

Estabelecidas as estratégias a serem empregadas no imunoensaio, o primeiro passo constitui-se na obtenção de anticorpos (Ac) num hospedeiro adequado. Existem dois tipos de Ac empregados em imunoensaios: os policlonais e os monoclonais. Os Ac monoclonais apresentam maior especificidade que os policlonais, afinidade por um epitopo específico e menor probabilidade de reatividade cruzada entre Ag similares ${ }^{6,24,44,45}$. A escolha do tipo de Ac dependerá, entretanto, do seu destino. Em geral, em análise ambiental é preferível o uso de Ac policlonais, especialmente quando se quer analisar uma classe de poluentes na sua totalidade ${ }^{29}$. 


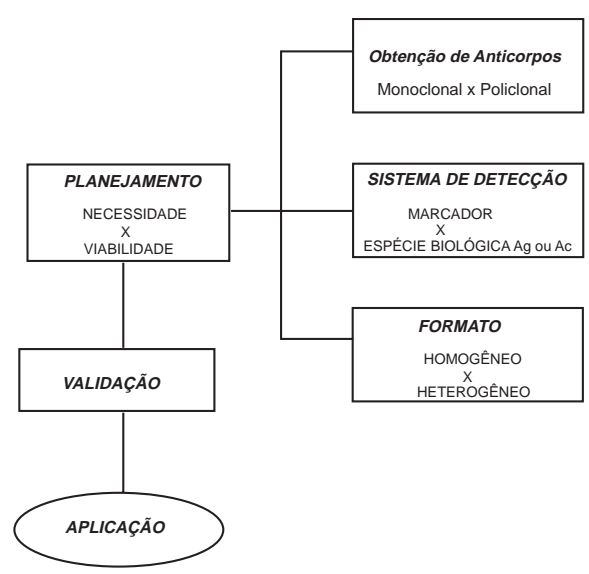

Figura 4. Organograma da confecção de um imunoensaio.

Os anticorpos policlonais são obtidos através de imunização em hospedeiro adequado. Quando a titulação é satisfatória, o sangue é coletado da veia central da orelha ou por punção cardíaca. Separa-se o soro por centrifugação e obtém-se mistura de anticorpos que se ligam a diferentes epitopos do hapteno conjugado, além de anticorpos oriundos da resposta a outros imunógenos presentes no organismo ${ }^{46}$. Se necessário, pode-se separar o anticorpo desejado por cromatografia de bioafinidade ${ }^{4,29}$.

Já os anticorpos monoclonais são produzidos por linhagem segregada e imortalizada de linfócitos B. Num primeiro passo, imuniza-se um hospedeiro, estimulando-se a população de linfócitos produtores do anticorpo desejado. Estes, entretanto, podem sobreviver em culturas por poucos dias. Para contornar esta limitação, células malígnas de linfócitos são incubadas separadamente. Estas, por sua vez, apresentam limitações quanto à produção de anticorpos e muitas vezes requerem suprimento da enzima hipoxantina fosforribosiltransferase (HPRT). As células malignas são, então, fundidas aos linfócitos B, originando hibridomas, que produzirão os anticorpos monoclonais e de maneira permanente. $\mathrm{O}$ esquema de produção de anticorpos monoclonais é ilustrado na Figura 5.

Produzidos os anticorpos, a etapa seguinte consiste na aplicação destes na análise de antígenos ou haptenos de interesse através da metodologia pré-estabelecida.

\section{Aplicações Analíticas em Imunoensaios: Interações Antigeno-Anticorpo.}

As interações Ag-Ac ou hapteno-Ac são classificadas em primárias ou secundárias. Interações primárias envolvem exclusivamente a ligação do determinante antigênico (epitopo) com sítio ligante (paratopo) do anticorpo específico. O equilíbrio químico destas interações primárias (Fig. 6) pode ser estudado utilizando-se haptenos $(\mathrm{H})$, em razão de que estes são univalentes e unideterminados ${ }^{47}$.

Já reações secundárias ocorrem entre Ac e Ag multivalentes, resultando em aglutinação ou precipitação do polímero Ag-Ac formado (Fig. 7).

As aplicações analíticas das interações secundárias são limitadas, reduzindo-se a reações de aglutinação e de precipitação em reações semiquantitativas, como por exemplo, a determinação da tipagem sangüínea ${ }^{17,48}$. Um cuidado a ser tomado em reações de aglutinação é o efeito da diluição, havendo comprometimento da mesma, tanto em concentrações elevadas (prozona), quanto muito diluídas do soro $^{46,49}$ (Fig.8).

\section{Interações Primárias}

Em imunoensaios quantitativos utilizam-se exclusivamente reações primárias entre anticorpos e haptenos; estes podem ser

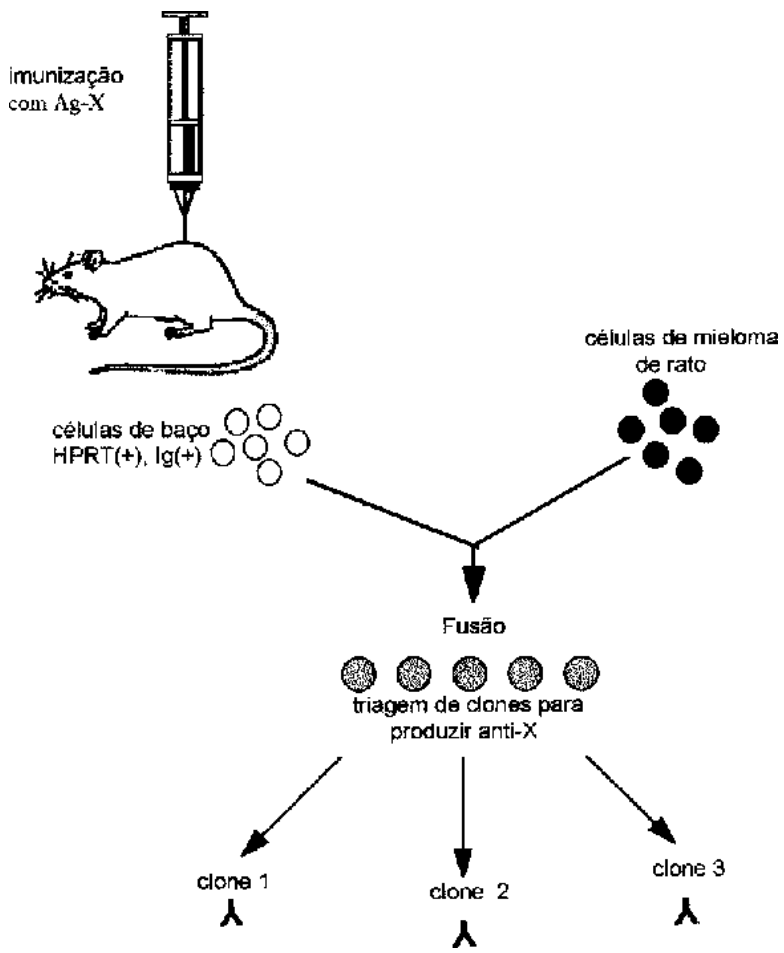

Figura 5. Esquema de produção de anticorpos monoclonais.

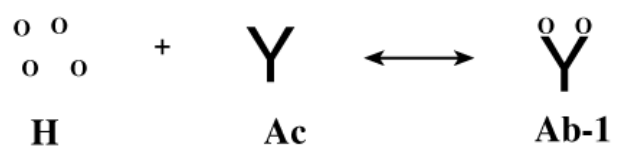

Figura 6. Interação primária entre haptenos e anticorpos.

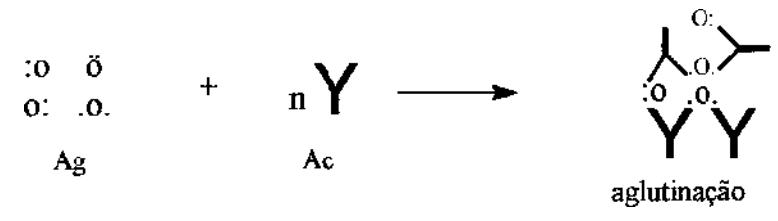

Figura 7. Interação secundária entre antígenos e anticorpos.

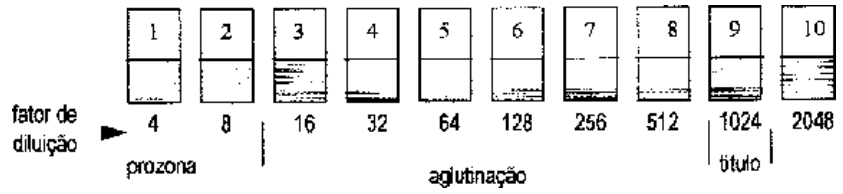

Figura 8. Efeito da diluição em reações de aglutinação.

classificados com base nos seguintes aspectos: a) homogeneidade, considerando-se, homogêneos quando não são necessárias separações para medição, ou heterogêneos quando se requer um passo adicional de separação; b) sobre qual espécie Ac ou Ag será introduzido um marcador; c) o tipo de marcador ou detecção empregado; d) o tipo de anticorpo utilizado, monoclonal ou policlonal; e) e finalizando se o ensaio será competitivo ou não competitivo ${ }^{6,13,29,36}$.

\section{Imunoensaios heterogêneos}

Constituem a maioria dos imunoensaios, necessitando para a quantificação precisa, de etapa adicional para separação das frações livres e ligadas da espécie marcada (Ag ou Ac). 
Estes ensaios são caracterizados pela inércia físico-química do marcador(*), ou seja não ocorre mudanças significativas no sinal que seria emitido pelo marcador após a complexação (AcAg* ou Ac*-Ag), fato este que justifica a etapa de separação para quantificação ${ }^{28}$. Estes imunoensaios são, na maioria, ensaios competitivos.

$$
\mathrm{nAc}+\mathrm{xAg}+\mathrm{yAg} * \longleftrightarrow(\approx \mathrm{n}-\mathrm{y}) \mathrm{Ac}-\mathrm{Ag}+(\approx \mathrm{n}-\mathrm{x}) \mathrm{Ac}-\mathrm{Ag} *
$$

Exemplo de imunoensaio heterogêneo não competitivo é o ensaio tipo sanduíche (Fig. 9) que segue as seguintes etapas:

a) Preparação de fase sólida com excesso de Ac.

b) Incubação com analito (Ag).

c) Incubação com excesso de Ac*.

d) extração do Ac* livre e medição.

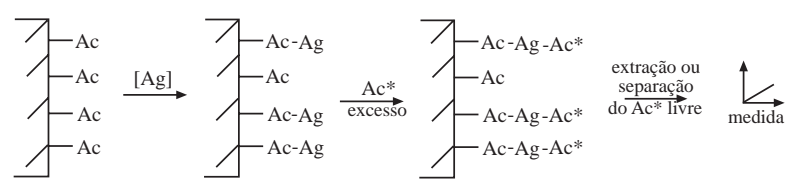

Figura 9. Esquema de imuno ensaio tipo sanduíche.

O tipo de detecção dependerá do marcador utilizado, sendo os mais comuns os radioimunoensaios e enzima-imunoensaios.

\section{a-Radioimunoensaios (RIAs)}

São em geral, imunoensaios competitivos, em que o nível de analito é extrapolado na curva de calibração.

Os radioligantes são contados em níveis de sensibilidade da ordem de picogramas. Estes limites de detecção, que chegam até $10^{-14} M$, dependem diretamente da sensibilidade dos isótopos. Entre os mais utilizados tem-se ${ }^{125} \mathrm{I},{ }^{3} \mathrm{H}$ e ${ }^{14} \mathrm{C}$ com radioatividades específicas de $2170 \mathrm{Ci} / \mathrm{mmol}, 29,2 \mathrm{Ci} / \mathrm{mmol}$ e $62,4 \mathrm{Ci} / \mathrm{mmol}$, respectivamente ${ }^{50,51}$. Embora o ${ }^{125} \mathrm{I}$ apresente maior nível de radioatividade específica, há a desvantagem deste diminuir a similaridade entre o radioligante e o hapteno a ser analisado. As principais vantagens deste método são o baixo custo do equipamento utilizado para detecção e a vasta literatura disponível ${ }^{18}$.

\section{$b$ - Enzima-imunoensaios (EIAs)}

Enzimas são os marcadores mais utilizados na atualidade, com as vantagens de não apresentarem riscos associados à exposição de radioisótopos, bem como outras como a possibilidade da amplificação catalítica (uma única enzima pode gerar várias espécies detectáveis) e da associação com outros marcadores, como por exemplo os quimiluminescentes e fluorescentes, resultando em ensaios de baixo limite de detecção ${ }^{44,52}$.

O exemplo significativo mais clássico de EIAs heterogêneos é o ELISA. Este método emprega anticorpos imobilizados em placa de poliestireno com número variável de poços de ensaio (Fig. 10). Este método é realizado em 8 etapas: 1- ativação da placa, 2lavagem, 3- imobilização dos anticorpos, 4- lavagem, 5- incubação, 6- lavagem, 7- adição de substrato cromogênico e 8- leitura óptica dos poços. Este sistema de placas possibilita a realização do ensaio ensaio de maneira com que garanta a uniformidade de todas as etapas tanto para as amostras e referências, condição essencial para a confiabilidade dos dados. Outro ponto é que devido a alta sensibilidade do método, o mesmo é feito em microescala, o que o torna bastante econômico dado a reduzida quantidade de reagentes utilizada, além da rapidez do método.

Pode operar de forma competitiva (Fig. 9) ou não competitiva. Na versão competitiva, antígenos marcados com enzimas competem com antígenos livres (analito) por número limitado de anticorpos imobilizados. Depois do período de

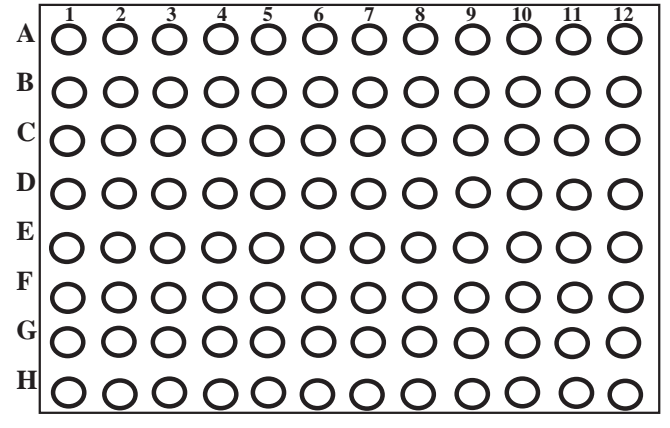

Figura 10. Kit para ensaio ELISA.

incubação (1 a 4 horas) a placa é lavada para remoção de espécies não ligadas. Em seguida, adiciona-se excesso de substrato e mede-se a atividade enzimática. Esta será inversamente proporcional à concentração do analito. Nesta tecnologia, a curva de calibração e a análise propriamente dita são feitas simultaneamente sob condições padronizadas. Atualmente utilizam-se, tanto para ensaios competitivos, quanto não competitivos, sistemas que fazem, além de leituras automatizadas dos diferentes poços, diluições em série e réplicas das amostras ${ }^{53}$.

Há, ainda, fluoroimunoensaios que podem ser desenvolvidos independentemente de reações enzimáticas, para modelos heterogêneos e homogêneos ${ }^{17,29}$.

\section{Imunoensaios homogêneos}

Imunoensaios homogêneos são menos freqüentes que os heterogêneos, pois requerem interações $\mathrm{Ac}-\mathrm{Ag} *$ ou $\mathrm{Ac} *-\mathrm{Ag}$, que provoquem mudanças significativas de sinal para $\mathrm{O}$ marcador ${ }^{19}$. Enzimas e fluoróforos representam os marcadores mais comumente utilizados nestes experimentos ${ }^{17}$.

A técnica mais utilizada entre os enzima-imunoensaios homogêneos é o EMIT. Neste ensaio, a atividade da enzima conjugada ao hapteno é modulada pelo ligante.

Fluoroimunoensaios são, em geral, baseados na transferência de energia de excitação do antígeno ou hapteno marcado para o anticorpo também marcado. Este efeito resulta em intensificação da fluorescência e ou pode ter efeito reverso resultando na supressão da fluorescência no caso de interação entre espécies marcadas com espécies não marcadas. Fluoresceína e rodamina são utilizados, respectivamente, como marcadores doadores e aceptores ${ }^{17}$.

De um modo geral, imunoensaios homogêneos apresentam como vantagens menor número de etapas, o que resulta em maior precisão e ganho em tempo. Entretanto, enzima-imunoensaios convencionais, como EMIT, CEDIA (Cloned Enzyme Donor ImmunoAssay), bem como alguns fluoro-imunoensaios apresentam limitação, quanto à sensibilidade ${ }^{28}$.

Apesar disto, por estes ensaios não requererem etapas de separação, são focos de intensas investigações. Especialmente o desenvolvimento de imunoensaios para detecção de analitos como agrotóxicos ${ }^{17,29}$ e fármacos ${ }^{17,54}$ em matrizes complexas como amostras brutas (ambientais ${ }^{29}$ e sangue ${ }^{54}$, entre outras) sem a necessidade de tratamento da amostra por separação ou lavagens tem sido alvo de muita investigação ${ }^{28}$.

\section{RECENTES UTILIZAÇÕES DE IMUNOENSAIOS APLICADOS À QUímICA ANALÍTICA}

Basicamente, os avanços no desenvolvimento de imunoensaios tem como meta satisfazer necessidades analíticas, como a simplicidade (imunoensaios homogêneos) ${ }^{20,27,54}$, sensibilidade (>zeptomoles, 1 zeptomol $=602$ moléculas $)^{7,44,55}$, análises multiplas (reação cruzada para um grupo ou classe) ${ }^{41,56}$, uso de 
marcadores não radioativos ${ }^{42,44}$, reprodutibilidade e estabilidade do sistema (sistemas reutilizáveis) ${ }^{14,57}$ e rapidez r $^{2,4,19,24}$.

\section{Imunoensaios homogêneos}

Técnica mais recente empregada com o intento de se aumentar a sensibilidade destes imunoensaios é a LOCI (Luminescente Oxygen Channeling Immunoassay) ${ }^{58}$. Esta técnica utiliza duas populações de micropartículas $(250 \mathrm{~nm})$ adsorvidas em cadeias distintas dos pares que formam anticorpos monoclonais. Uma população é preenchida com corante "bromosquaraine" e a outra com um precursor de molécula quimiluminescente (tioxeno), juntos com um fluoróforo (quelato de európio). Um antígeno TSH (thyroid stimulating hormone) forma ponte entre diferentes partículas como resultado da ligação do par de cadeias emparelhadas de anticorpos monoclonais. Irradiação da mistura reacional com laser produz oxigênio singlete na superfície da partícula carregada com corante e esta espécie ativa difunde-se para partículas adjacentes, gerando dioxetano, que decompõe e transfere energia para o fluoróforo, o qual então emite luz. Este processo só ocorre em partículas ligadas ao antígeno. Qualquer oxigênio singlete gerado em solução é inapto a interagir com a partícula contendo tioxeno (precursor do dioxetano). Este ensaio apresenta rapidez (12 min) e alta sensibilidade, com limite de detecção para TSH menor $0,0125 \mathrm{mUI} / \mathrm{L}(0,002 \mathrm{ng} / \mathrm{mL})^{58}$.

Ensaios homogêneos foram desenvolvidos também baseados em sistemas amperométricos de detecção ${ }^{59,60}$.

Recentemente, foram desenvolvidos ensaios homogêneos, NEEIA (Nonseparation Electrochemical Enzyme ImmunoAssay), com formatos não-competitivo (tipo sanduiche) ${ }^{61,62}$ e competitivo $^{54}$. Estes ensaios basearam-se no uso de eletrodo de ouro com microporos, o qual funcionou, tanto como eletrodo de trabalho, quanto como fase sólida para imobilização de anticorpos através de uma camada quimissorvente polimérica $^{54}$. A versão competitiva deste imunoensaio é ilustrada na Figura 11.

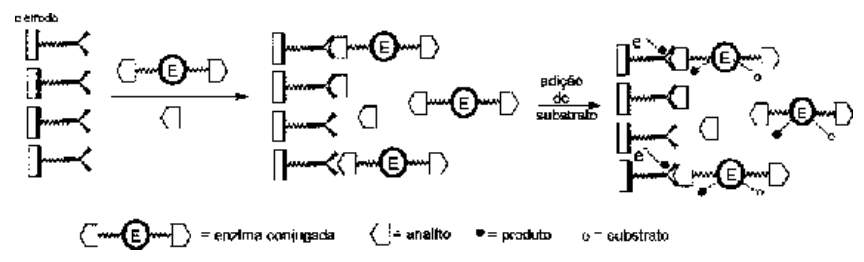

Figura 11. Esquema da versão competitiva do NEEIA.

No ensaio representado na Figura 11, utilizou-se a enzima fosfatase alcalina como marcador do analíto. $\mathrm{O}$ analito marcado compete, então, com analito livre por um número limitado de anticorpos imobilizados na interface do eletrodo. Após perído de incubação de 30 a $60 \mathrm{~min}$, adiciona-se substrato ( $p$ aminofenilfosfato) que é catalisado a $p$-aminofenol, espécie eletroativa em contato com o eletrodo.

Este método foi utilizado na detecção de glicosídeos cardiotônicos como digoxina e digitoxina, com limites de detecção de $0,1 \mathrm{n} M$ e $10 \mathrm{n} M$, respectivamente. Verificou-se que em amostras brutas de soro não houve perda de sensibilidade para concentrações acima de $1 \mathrm{n} M^{54}$.

\section{Sistemas de injeção em fluxo acoplados a IAs (FIIA)}

Entre os avanços nas automatizações de imunoensaios, incluem-se o desenvolvimento de sistema acoplados à FIA, os quais contribuem enormemente para o aumento da velocidade de imunoensaios ${ }^{17,19}$. Estes têm sido usados tanto em IAs homogêneos quanto em heterogêneos.
Além da redução do tempo de análise, uma das vantagens oferecidas por estes sistemas, especialmente quando acoplados a IAs heterogêneos é a redução dos passos de lavagem e o fato de que o imunorreator age concentrando a amostra ${ }^{19}$. A fase sólida é usualmente feita ligando-se um anticorpo ou antígeno a partículas pré-ativadas, membranas, capilares ou outras matrizes de alta área superficial ${ }^{14}$. O glutaraldeído é um dos reagentes bifuncionais mais utilizados na imobilização destas espécies nestes tipos de suporte ${ }^{3}$. A escolha do suporte para o qual o Ac ou Ag será imobilizado é de fundamental importância. Adsorções não específicas devem ser mantidas a valor mínimo, evitando-se, assim, influência nos valores de "background" e na sensibilidade do método ${ }^{19}$, bem como na durabilidade da fase sólida ${ }^{14}$.

Embora a imobilização de antígenos apresente vantagens sobre a imobilização de anticorpos, esta requer reações específicas e orientação adequada, fato este que dificulta sua operação ${ }^{63}$. Entre os suportes mais comumente empregados na confecção destes imunorreatores estão: agarose, celulose, resinas, polímeros, sílica modificada ${ }^{19}$. Estes imunorreatores são também referidos como colunas de imunoafinidade. Entretanto, não se pode generalizar, a comparação de FIA com cromatografia por imunoafinidade ${ }^{2}$.

Recentemente, foram desenvolvidas e comparadas duas técnicas de imunoensaios para análise do herbicida atrazina. Uma delas seguiu os moldes do ELISA e outra adaptou a mesma à FIA $^{7}$. Nestas investigações observou-se ganho em tempo de análise de $1 \mathrm{~h}$ para 20 minutos, assim como a possibilidade de se reutilizar o imunorreator por até 70 vezes, sem perda do desempenho. O ELISA apresentou alta sensibilidade, detectando limites de até $9 \mathrm{ng} / \mathrm{L}$ contra $75 \mathrm{ng} / \mathrm{L}$ para o FIIA $^{7}$. Outro exemplo de imunoensaio reutilizável, emprega coluna simples de troca iônica empacotada com sefarose e eluída com $50 \mathrm{mM}$ de tampão(malonato) $\mathrm{pH} 5$ para análise de um alergeno ${ }^{2}$. Este ensaio baseou-se na interação entre alergeno 2,4dinitrobenzenosulfonato de sódio (DNP) conjugado a albumina bovina (BSA) e os respectivos anticorpos (IgE) marcados com isotiocianato de fluoresceína. A intensidade de fluorescência medida mostrou correlação linear com a concentração do alergeno na faixa de $0,01-2,00 \mathrm{mg} / \mathrm{mL}$ e a separação baseou-se nos diferentes pontos isoelétricos dos complexos (Fig. 12).

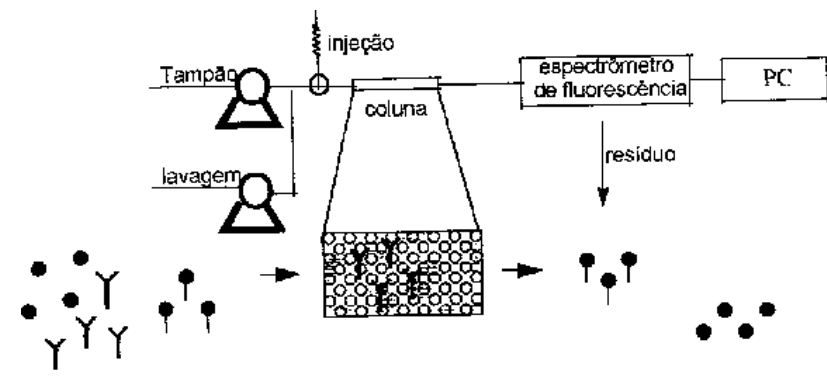

$$
Y=\operatorname{lgE} \text { FITC } \quad=\text { = DNF-BSA } \quad=\text { complexo alergenc-anticorpo }
$$

Figura 12. Diagrama esquemático de FIIA para detecção de alérgeno $D N P$.

\section{Cromatografia por imunoafinidade}

Consiste num dos meios mais eficazes de purificação e determinação de traços em amostras complexas. Neste sistema o analito é retido seletivamente pelo respectivo anticorpo imobilizado na coluna, enquanto demais componentes são eliminados na eluição ${ }^{35,64}$. Basicamente, a diferença entre fase sólida de imunorreatores em FIA e matrizes de fase estacionária está na nomenclatura. Resulta daí que as principais matrizes que podem ser ativadas para imobilização de anticorpos são comuns, entre 
estas: agarose, celulose, dextrano, poliacrilamida, trisacril, alumina e sílica ${ }^{64}$. Apesar da grande seletividade obtida, com emprego de anticorpos na confecção de fases estacionárias, há, ainda, na maioria dos casos influência de interferentes nos limites de detecção ${ }^{4}$.

Recentemente, foi desenvolvido um imunoensaio em que se utilizaram duas micro-colunas aplicadas à detecção de insulina em amostras biológicas complexas. $\mathrm{Na}$ dosagem em questão utilizou-se uma segunda coluna de fase reversa em linha com uma coluna por imunoafinidade. $O$ sistema coletava a fração eluída da coluna por imunoafinidade e injetava na segunda coluna, onde eram separados e reconcentrados outros componentes. Esta combinação resultou no ganho da seletividade e limite de detecção $(10 \mathrm{fmol})$, utilizando detector $\mathrm{UV}$, em relação a sistemas com coluna simples ${ }^{4}$. Outras vantagens destas microcolunas conjugadas foram o reduzido volume de amostra $(\approx 100 \mu \mathrm{L})$ e a rapidez de análise ${ }^{4}$.

\section{Imunossensores}

Anticorpos podem ser utilizados como reagentes altamente seletivos em biossensores. Enquanto em eletrodos enzimáticos ou baseados em microrganismos são monitorados concentrações de substratos ou produtos, os imunossensores são baseados nos princípios de fase sólida de imunoensaios e nos eventos físicoquímicos resultantes da interação $\mathrm{Ac}-\mathrm{Ag}^{21,41}$. Uma das limitações dos imunossensores é que a interação Ac-Ag não é prontamente reversível ${ }^{65}$. Este fato pode ser contornado utilizando-se anticorpos de baixa afinidade ou agentes capazes de provocar dissociação do complexo Ac-Ag. Nos imunossensores são detectadas as concentrações de $\mathrm{Ac}$ ou Ag, tanto por mudanças diretas no transdutor, quanto por deslocamento no equilíbrio de reações (imunoensaios típicos) ${ }^{66}$. Os principais transdutores empregados são os eletroquímicos (amperométricos ${ }^{67,68}$, potenciométricos ${ }^{69,70}$, condutométricos ${ }^{71,72}$ ), ópticos (onda evanescente ${ }^{73,74}$, ressonância superfícial de plasma ${ }^{75}$, espectroscopia de interferência reflectométrica ${ }^{76}$ ) e os piezoelétricos ${ }^{77,78}$.

Recentemente, foi desenvolvido um imunoeletrodo contendo anti-IgG finamente disperso em partículas de carbono (centenas de angstrons) ${ }^{26}$. O método foi baseado em imunoensaios do tipo sanduíche (Fig.9), sendo parte do analito marcada com peroxidase. O método foi combinado a FIA e testado na detecção de $\mathrm{IgG}$, apresentando limites de detecção de $10 \mathrm{p} M$ em tempo não superior a $20 \mathrm{~min}$. A adsorção não específica de proteínas sobre o eletrodo foi praticamente nula e houve boa reprodutibilidade do sistema ${ }^{26}$.

Outro eletrodo a utilizar carbono como condutor foi o empregado no imunoensaio simultâneo de fenitoína e fenobarbital ${ }^{57}$. Neste experimento competitivo (Fig. 13), os analitos foram respectivamente marcados com sais de ferrocenoamônio $(0,26 \mathrm{~V}) \mathrm{e}$ cobaltoceno $(-1,05 \mathrm{~V})$. O experimento, embora não esteja relacionado diretamente a imunossensores, expõe a possibilidade de desenvolver sistemas para multianalitos usando marcadores de diferentes potenciais redox ${ }^{57}$.

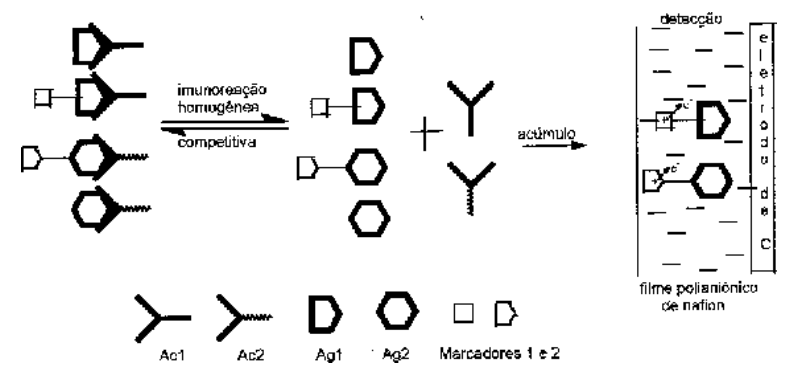

Figura 13. Imunoensaio para análise simultânea de dois analitos utilizando eletrodo de pasta de carbono modificado com filme polimérico aniônico (Nafion).
O uso de filmes poliméricos na confecção de imunossensores amperométricos ${ }^{79-81}$, assim como o desenvolvimento de sistemas com superfícies renováveis têm sido bastante explorados ${ }^{23}$.

O monitoramento ambiental de poluentes em amostras de águas por biossensores eletroquímicos (imunossensores, sensores enzimáticos e microbianos) foi recentemente revisado ${ }^{82}$.

Os imunoensaios aplicados à detecção e quantificação de poluentes tóxicos no ambiente tem atraído atenção de muitos pesquisadores. Entretanto, apesar das inúmeras vantagens oferecidas por estes métodos, há poucos exemplos de detecção direta. Experimento baseado em detecção direta por imunossensores piezolétricos foi desenvolvido, recentemente, para o ácido 2,4-fenoxiacético, um agrotóxico. Neste sistema, os cristais piezoelétricos foram modificados com o hapteno (ácido 2,4-diclorofenoxiacético) conjugado à superfície de eletrodos de ouro ativados com moléculas como aminotiofenol (Fig. 14), cisteamina, cistina ou outras contendo grupos silanol ${ }^{34}$.

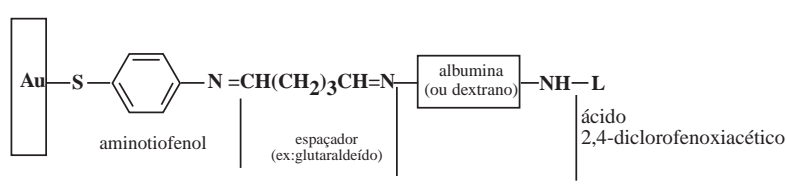

Figura 14. Representação superfície do imunossensor piezoelétrico modificado com ácido 2,4-diclorofenoxiacético.

No experimento foram testados entre outras modificações a conjugação do hapteno com albumina e dextrano. O princípio do método baseou-se na competição entre moléculas do agrotóxico imobilizadas e livres, por anticorpos livres em solução. A quantidade de anticorpos que se ligam ao eletrodo é inversamente proporcional à concentração do analito. Esta ligação, por sua vez, provoca mudanças na freqüência da microbalança de quartzo. Em geral os sistemas piezoelétricos apresentam limitações quanto a especificidade, entretanto no experimento em questão obteve-se boa especificidade, mostrando ser bastante promissor para análise de agrotóxicos ${ }^{34}$.

\section{CONCLUSÕES}

As exigências das legislações nacionais e internacionais em questões ambientais têm aumentado nos últimos anos. Neste sentido, é necessário contínuo desenvolvimento e aperfeiçoamento de novas técnicas imunoanalíticas para investigação de amostras complexas como sangue e amostras ambientais.

As tendências atuais da utilização de imunoensaios aplicados à Química Analítica apontam para o desenvolvimento de imunoensaios mais rápidos, tais como os homogêneos ou outros imunoensaios acoplados a FIA ou cromatografia por imunoafinidade; a utilização de sistemas de detecção não radioativos, como por exemplo imunossensores, e o desenvolvimento de métodos para análise de multianalitos.

Vale ressaltar ainda o uso promissor de marcadores como acetato quinase, moléculas quimiluminescentes e DNA somados a técnicas como PCR (polymerase chain reaction) e sistemas bi-enzimáticos como meios de aumentar a sensibilidade ${ }^{58}$.

Outro ponto em relação aos imunoensaios diz respeito a introdução deste tópico no currículo dos cursos de graduação e pós graduação, baseando-se no fato que o mesmo vem sendo feito em países desenvolvidos ${ }^{83}$.

\section{AGRADECIMENTOS}

Os autores agradecem à FAPESP e à FAEP pelo apoio financeiro concedido. 


\section{REFERÊNCIAS}

1. Laurino, J. P.; Hallett, J.; Kiessling, L. S.; Benson, M.; Pelletier, T.; Kuhn, C.; Annals Clin. Lab. Science 1997, 27, 230.

2. Lim, TK; Nakamura, N; Matsunaga, T.; Anal. Chim. Acta 1997, 354, 29.

3. Babkina; S. S.; Vinter, V. G.; Zainullina, A. S.; J. Anal. Chem. 1994, 49, 1188.

4. Shen, H; Aspinwall, C. A; Kennedy, R. T.; J. Chromatogr. B 1997, 689, 295.

5. Makower, A.; Barmin, A.; Morzunova, T.; Eremenko, A.; Kurochkin, I.; Bier, F.; Scheller, F.; Anal. Chim. Acta 1997, 357, 13.

6. Abad, A; Moreno, MJ; Montoya, A.; Anal. Chim. Acta 1997, 347, 103.

7. Gascon, J; Oubina, A; Ballesteros, B; Barcelo, D; and others; Anal. Chim. Acta 1997, 347, 149.

8. Sherry, J.; Chemosphere 1997, 34, 1011.

9. Kramer, P. M.; J. AOAC Int. 1996, 79, 1245.

10. Nunes, G. S.; Toscano, I. A.; Barcelo, D.; TRAC-Trends Anal. Chem. 1998, 17, 79.

11. Gerlach, R. W.; White, R. J.; Oleary, N. F. D.; VanEmon, J. M.; Water Res. 1997, 31, 941.

12. Tang, L. X.; Rowell, F. J.; Cumming, R. H.; Anal. Chim. Acta 1997, 347, 235.

13. Mercader, JV; Montoya, A.; Anal. Chim. Acta 1997, 347, 95.

14. Joyeux, C; Chrzavez, E; Boquien, C. Y.; Picque, D.; Anal. Chim. Acta 1996, 320, 77.

15. Issert, V.; Grenier, P.; BellonMurel, V.; Sciences des Aliments 1997, 17, 131.

16. Torres, C. M.; Pico, Y.; Manes, J.; J. Chromatog. A 1996, 754, 301

17. Purchades, R.; Maquieira, A.; Atienza, J.; Crit. Rev. Anal. Chem. 1992, 23, 301.

18. Jackson, T. M.; Ekins, R. P.; J. Immunol. Meth. 1986, 87, 13.

19. Purchades, R.; Maquieira, A.; Crit. Rev. Anal. Chem. 1996, 26, 195.

20. Krishnan, R.; Ghindilis, A. L.; Atanasov, P.; Wilkins, E.; Electroanalysis 1996, 8, 1131.

21. Skladal, P.; Electroanalysis 1997, 9, 737.

22. Lu, B.; Smyth, M. R.; Quinn, J.; Bogan, D.; Okennedy, R.; Electroanalysis 1996, 8, 619.

23. Santandreu, M.; Sole, S.; Fabregas, E.; Alegret, S.; Biosensors \& Bioelectronics 1998, 13, 7.

24. Kempe, M.; Anal. Chem. 1996, 68, 1948.

25. Mulchandani, A.; Bassi, A. S.; Crit. Rev. Biotech. 1995, $15,105$.

26. Krishnan,R.; Ghindilis, A. L.; Atanasov, P.; Wilkins, E.; Anal. Letters 1996, 29, 2615.

27. Melnichenko, O. A.; Eremin, S. A.; Egorov, A. M.; J. Anal. Chem. 1996, 51, 512.

28. Kricka, L. J.; Pure Applied Chem. 1996, 68, 1825.

29. Sherry, J. P.; Critical Rev. Anal. Chem. 1992, 23, 217.

30. Limoges, B.; Degrand, C.; Brossier, P.; J. Electroanal. Chem. 1996, 402, 175.

31. Kubitschko, S.; Spinke, J.; Bruckner, T.; Pohl, S.; Oranth, N.; Anal. Biochem. 1997, 253, 112.

32. Wang, J.; Pamidi, P. V. A.; Rogers, K. R.; Anal. Chem. 1998, 70, 1171.

33. Sadik, O. A.; John, M. J.; Wallace, G. G.; Barnett, D.; Analyst 1994, 119, 1997.

34. Horácek, J.; Skládal, P.; Anal. Chim. Acta 1997, 347, 43.

35. Yang, S. S.; Goldsmith, A. I.; Smetena, I.; J. Chromatogr. A 1996, 754, 3.

36. Yong, C. R.; Structural Requirements for Immunogenity and Antigenicity, in: Atassi, M. Z.; Van Oss, C. J.;
Absolom, D. R.; “Molecular Immunology", Eds., Marcel Decker, New York, 1984.

37. Benjamini, E.; Leskowitz, S.; "Immunology: A short course", ed, Alan R. Liss, New York, 1988, p.43.

38. Davies, D. R.; Metzger, H.; Ann. Rev. Immunol. 1983, 87,1 .

39. Benjamini, E.; Leskowitz, S.; "Immunology: A short course", ed, Alan R. Liss, New York, 1988, p.35.

40. Skelley, D. S.; Brown, L. P.; Besch, P. K.; Clin. Chem. 1973, 19, 146.

41. Jones, G.; Wortberg, M.; Rocke, D. M.; Hammock, B. D.; ACS Symp. Series 1997, 657, 331.

42. Adamczyk, M; Fishpaugh, JR; Heuser, KJ; Ramp, JM; Tetrahedron 1998, 54, 3093.

43. Girotti, S.; Ferri, E.; Ghini, S.; Roda, A.; Pasini, P.; Carrea, G.; Bovara, R.; Lodi, S.; Lasi, G.; Navarro, J.; Rauch, P.; Quim. Anal. 1997, 16, 111.

44. Tsuji, A.; Maeda, M.; Arakawa, H.; Anal. Sciences 1989, 5, 497.

45. Benjamini, E.; Leskowitz, S.; "Immunology: A short course”, ed, Alan R. Liss, New York 1988, p.112.

46. Mikkelsen, S.R., discussions, 1998.

47. Hawcroft, D.; Hector, T.; Rowell, F.; "Quantitative Bioassay”, Wiley, New York, 1987, p.91.

48. Nowotny, A., "Basic Exercises in Immunochemistry", Springler-Verlag, New York, 1979, p.219.

49. Higgins, KM; Davidian, M; Chew, G; Burge, H.; Biometrics 1998, 54, 19.

50. Butt, W. R.; "Practical Immunoassay" in: Butt, W. R., ed.; Marcel Decker, New York, 1984, p.1.

51. Bolton, A. E., "Immunoassay for the 80s"; in. Voller, A.; Bartlett,A.; Bidwell, D., ed.; University Park Press: Baltimore, 1981, p.69.

52. Szurdoki, F.; Kido, H.; Hammock, B. D.; ACS Symp. Series 1997, 657, 38.

53. Johannsson, A. in "Principles and Practice of Immunoassay" Pride, C., Newman, D., eds.; Macmillan, New York, 1991, p.300.

54. Ducey, MW; Smith, AM; Guo, XA; Meyerhoff, ME.; Anal. Chim. Acta. 1997, 357, 5.

55. Bier, F. F.; Ehrentreichforster, E.; Makower, A.; Scheller, F. W.; Anal. Chim. Acta 1996, 328, 27.

56. Bordes, A. L.; Limoges, B.; Brossier, P.; Degrand, C.; Anal. Chim. Acta 1997, 356, 195.

57. 2. Medyantseva, E. P.; Vertlib, M. G.; Budnikov, G. K; Babkina, S. S.; J. Anal. Chem. 1995, 50, 719.

58. Ullman, E. F.; "Bioluminescence and Chemiluminescence. Fundamentals and Applied Aspects", Wiley, Chichester 1994, p.16.

59. Vreeke, M.; Rocca, P.; Heller, A.; Anal. Chem. 1995, 67, 303.

60. Ivnitski, D.; Rishpon, J.; Biosens. Bioelectron. 1996, 11, 409.

61. Duan, C.; Meyerhoff, M. E.; Anal. Chem. 1994, 66, 1369.

62. Meyerhoff, M. E.; Duan, C.; Meusel, M.; Clin. Chem. 1995, 41, 1378.

63. Bier, F. F.; Stöcklein, W.; Böcher, M.; Bilitewski, U.; Schmid, R. D.; Sensors Actuators B 1992, 7, 509.

64. Collins, C. H.; Braga, G. L.; Bonato, P. S.; Introdução aos Métodos Cromatográficos, Editora da Unicamp, Campinas-SP 1990, 4 ed., p.117.

65. Miller, W. G.; Anderson, F. P.; Anal. Chim. Acta 1989, 227, 135 .

66. Pilar, M. M.; Barcelo, D.; Meas. Sci. Technol. 1996, 7, 1547.

67. Reeves, S. G.; Siebert, S. T. A.; Roberts, M. A.; Durst, R. A.; Trends Anal. Chem. 1995, 14, 351.

68. Medyantseva, E. P.; Vertlib, M. G.; Budnikov, G. K.; Babkina, S.S.; Eremin, S. A.; J. Anal. Chem. 1995, 50, 719.

69. Bush, D. L.; Rechnitz, G. A.; Anal. Lett. 1987, 20, 1781.

70. Yuaev, M. F.; Sitdykov, R. A.; Dmitrieva, N. M.; 
Dzantiev, B. B.; Zherdez, A. V.; Askarov, K. A.; J. Anal. Chem. 1995, 50, 194.

71. Sandberg, R. G.; Van Houten, L. J.; Schwartz, J. B. R. P.; Dallas, S. M.; Silvia, J. C.; Michael, A.; Narayanswamy, V.; ACS Symp. Ser. 1992, 511, 81.

72. Fare, T. L.; Cabelli, M. D.; Dahlin, C. D. T.; Dallas, S,M.; Thompson, P. H.; Schwartz, J. L.; Silvia, J. C.; Wiedman, S. S.; Polym. Mater. Sci. Eng. 1994, 71, 649.

73. Bier, F. F.; Schimid, R. D.; Biosens. Bioelectron. 1994, 9, 125.

74. Schipper, E.F.; Kooyman, R.P.H.; Heideman, R. G.; Greve, J.; Sens. Actuators B 1995, 24-25, 90.

75. Davies, R. J., Pollard-Knight, D.; Am. Biotech. Lab. 1993, July 1.

76. Brecht, A.; Piehler, J.; Lang, G.; Gauglitz, G.; Anal. Chim. Acta 1995, 311, 289.
77. Guilbault, G. G., Luong, J. H. T.; Food Sci. Technol. 1994, 60, 151.

78. Suleiman, A. A.; Guilbault, G. G.; Analyst 1994, 119, 2279.

79. Santandreu, M.; Cespedes, F.; Alegret, S.; Martinez Fabregas, E.; Anal. Chem. 1997, 69, 2080.

80. Blonder, R.; Katz, E.; Cohen, Y.; Itzhak, N.; Anal. Chem. 1996, 68, 3151 .

81. Lu, B; Iwuoha, EI; Smyth, MR; OKennedy, R.; Anal. Chim. Acta 1997, 345, 59.

82. Chemnitius, G.; Meusel, M.; Zaborosch, C.; Knoll, M.; Spener, F.; Cammann, K.; Food Technol. Biotechnol. 1996, 34, 23.

83. Kellner, R., Mermet, J. M., Otto, M., Widmer, H. M, ed., The Approved Text to FECS Curriculum Analytical Chemistry, Wiley, 1997. 